\title{
PROCESSOS PSíQUICOS DO ENGRAVIDAMENTO NA ADOLESCÊNCIA EM CONTEXTOS DE PERIFERIA: IMPASSES E POSSIBILIDADES
}

\author{
Maria Aparecida Loss ${ }^{1}$ e Clary M. Sapiro ${ }^{2}$ \\ Universidade Federal do Rio Grande do Sul.
}

Este artigo apresenta resultados parciais de uma análise de conteúdo realizada a partir de sessões em grupo, envolvendo adolescentes, em um ambulatório de saúde pública na cidade de Porto Alegre, Rio Grande do Sul. Nosso objetivo foi investigar adolescentes que vivem em uma comunidade de periferia, situando seus processos psicológicos de antecipação quanto às possibilidades de engravidar. A coleta de dados consistiu em "versos de rap" escritos pelas adolescentes participantes em 10 sessões terapêuticas de grupo, bem como fragmentos de um manual técnico e educacional relativo à saúde sexual e reprodutiva, o qual constitui ferramenta de trabalho na Saúde Pública. As categorias emergentes da análise de conteúdo revelaram a inadequação $e$ a distância entre a linguagem e a cultura das adolescentes e os conteúdos desses manuais, implementados como instrutivos e educacionais. Enfatizamos, ainda, os aspectos subjetivos e inconscientes que envolvem a procriação humana, sugerindo o neologismo "engravidamento" como um processo psíquico na adolescência.

Descritores: Gravidez na adolescência. Sexualidade feminina. Processos psicoterapêuticos.

1 Psicóloga da Rede Municipal de Saúde, em Porto Alegre e Mestranda do Programa de Pós-Graduação em Psicologia Social e Institucional da Universidade Federal do Rio Grande do Sul. Endereço Eletrônico: maria.loss@ufrgs.br

2 Profa. Adjunta, Pesquisadora do Programa de Pós-Graduação em Psicologia Social e Institucional da Universidade Federal do Rio Grande do Sul. Endereço Eletrônico: sapiro@ufrgs.br 
1 este artigo, examinamos as experiências singulares do processo de enferia, podemos afirmar que as adolescências vividas pelos sujeitos deste estudo demonstraram a importância de fazermos foco sobre as cenas locais: começando pelas diferenças de gênero, passando pelas configurações familiares e geracionais, pelos valores culturais e pelas contingências sociais.

Essa temática nos desafia à formação de um novo paradigma, pois implica a construção de teorias que possam dar conta de uma engrenagem sutil e de uma articulação permanente entre o sujeito adolescente, seu tempo e sua cultura.

Nossa implicação, relativa à gravidez na adolescência, surgiu a partir da experiência da primeira autora no atendimento de adolescentes em um Centro de Saúde, situado numa comunidade pobre na cidade de Porto Alegre, Rio Grande do Sul. A modalidade de atendimento em grupo viabiliza os processos de simbolização e de construção de narrativas entre os sujeitos adolescentes, os quais podem constituir novos sentidos para as experiências vividas.

A realização de uma "oficina de Rap" ${ }^{3}$ em um grupo terapêutico, no período de março a maio de 2004, nesse local, teve como propósito instaurar entre os participantes um movimento de "contar sua história” ou "narrar uma experiência”. A partir da construção dessas histórias, evidenciou-se no grupo uma marca relativa às diferenças de gênero. A produção escrita de adolescentes do sexo feminino deixou emergir um imaginário decorrente do exercício sexual incipiente e das possibilidades de engravidar. Adotamos o termo engravidamento para enfatizar um processo de cogitação quanto à condição de possibilidade de procriação, inaugurada na puberdade e instaurada pela atividade sexual.

3 “Rap” é uma manifestação musical e também uma atitude relativa ao movimento Hip-Hop, que vem consagrar a narrativa como modo de transmissão oral de experiências. 
No momento em que escrevemos este texto, os sujeitos participantes não estão em atendimento, portanto, utilizamos dados contidos em prontuários, observando a Resolução Normativa de 09 de janeiros de 1997 (01/97) da Comissão de Pesquisa e Ética em Saúde e respeitando as Diretrizes Éticas Internacionais e as Diretrizes e Normas Regulamentadoras de Pesquisas Envolvendo Seres Humanos (CIOMS 1993 e Resolução CNS 196/96), as quais destacam o compromisso com a privacidade e confidencialidade dos dados utilizados ${ }^{4}$.

A nossa investigação incluiu a análise de conteúdo dessa produção e também do conteúdo impresso no manual técnico e educativo utilizado para a abordagem da saúde sexual dos adolescentes, no âmbito da atenção básica no campo da saúde pública.

Na primeira análise, o próprio grupo identificou três categorias: "se apaixonar e perder a razão"; "engravidar e não saber o que fazer”; "ser mulher e saber se cuidar”. Para a segunda análise, as categorias foram: “a justificativa para prestação da assistência”; "a relação entre partos e contaminação pelo HIV” e “a banalização da relação sexual”.

Optamos em revisar as contribuições da teoria psicanalítica sobre a adolescência, desenvolvendo três tópicos: a descrição do contexto; a descrição da atividade de grupo, seguida da produção escrita das adolescentes e das categorias de análise; e a apresentação da análise documental.

4 As três adolescentes que selecionamos para este trabalho representam casos retrospectivos e nossa descrição respeita os critérios estabelecidos no Termo de Compromisso para Uso de Dados. Submetemos à Comissão de Ética e Pesquisa da Universidade Federal do Rio Grande do Sul o Projeto de dissertação de Mestrado As Possibilidades do Engravidamento na Adolescência: Considerações Sobre a Construção da Sexualidade Feminina em Contextos de Periferia. Nesse documento, destacamos que o acesso privilegiado aos dados decorreu da prática clínica da primeira autora, no ano de 2004, e que partimos de dados já registrados, tomando as precauções de descaracterizar os sujeitos. 


\section{Descrição do contexto: a interface entre a adolescência, atenção pri- mária e a saúde mental coletiva}

Partimos da experiência de uma das autoras no campo da saúde pública, mais especificamente no campo da saúde mental coletiva, em um Centro de Saúde Municipal, situado em uma comunidade na periferia da cidade de Porto Alegre. Nesse local, organizou-se um projeto de Acolhimento para todos os usuários, a partir da formação de grupos por faixa etária.

A forma de receber o paciente, encaminhado para o serviço de saúde mental por meio de grupos de acolhimento, pode propiciar uma mudança na cultura da saúde pública, na visão centrada na medicação e no modelo de consultas individuais. As condições de enunciação que orientam os discursos no grupo “de iguais” diferem das condições de enunciação numa cônsulta individual, à medida que produzem, no mínimo, um descentramento de olhares na relação médico-paciente, um deslocamento das posições e dos lugares a serem ocupados pelos sujeitos no modelo de assistência "queixasolução".

Uma questão a situar, que é de grande importância, refere-se ao fato de esse serviço realizar um trabalho de consultoria junto às equipes da rede de atenção básica ${ }^{5}$. Nessas consultorias, os(as) agentes comunitários(as) ${ }^{6}$ de saúde demonstram estar preocupados com o aumento do número de gestações na adolescência e, muitas vezes, banalizam a sexualidade desses jovens, dizendo que sua vida sexual "começa aos 10 anos".

5 As unidades básicas de saúde (UBS) são compostas por equipes de atenção primária, as quais podem ser organizadas como serviços de ambulatório ou como programas de saúde da família (P.S.F.). Os PSFs são constituídos por uma equipe mínima: um médico geral comunitário, um enfermeiro, quatro auxiliares de enfermagem e quatro agentes comunitários de saúde.

6 Os agentes comunitários de saúde pertencem à comunidade onde o serviço está inserido, e são contratados e treinados para promover a atenção em saúde básica, o que chamamos de atenção primária, uma vez que o principal objetivo é prevenir a instalação da "doença”. O procedimento e a atuação principais desses agentes é o acesso ao domicilio do paciente por meio de visitas freqüentes, mapeadas em trajetos específicos para cada um. 
Processos Psíquicos do Engravidamento na Adolescência em Contextos de Periferia

Segundo esses agentes, a maioria das "meninas" abandona a escola, rompe com o parceiro e, como resultado disso, fica “deprimida”. E quando o bebê nasce, essas mães “dão” o filho para outros cuidarem. Muitas delas não fazem o pré-natal, ou melhor, não vêm às consultas de acompanhamento pré-natal, porque se sentem sozinhas ou envergonhadas.

Essa percepção é corroborada por inúmeras pesquisas nacionais, que apontam para um incremento da gestação na adolescência nas camadas sociais mais baixas, nas quais aparecem, como conseqüência, o abandono da escola e a constituição de núcleos familiares monoparentais inseridos em famílias extensas (avós, pais e irmãos) ou mistas (com tios, padrastos/ma-drastas e ascendentes ou descendentes destes).

Sant’Anna (2001) chama a atenção sobre o início, cada vez mais precoce, da puberdade e da idade da menarca, o que tem acarretado uma antecipação da iniciação sexual, mas não uma antecipação da maturação emocional. Portanto, alguns fatores de imaturidade emocional podem ser decisivos para a ocorrência de uma gestação: pensamento mágico, confirmação da fertilidade, agressão aos pais, sentimento de culpa, desejo de ser mãe (decorrente e como solução para suas dificuldades no relacionamento familiar, carência afetiva e baixa auto-estima). A autora aponta ainda para uma correlação entre baixa escolaridade e iniciação sexual precoce.

As pesquisas indicam que, nos últimos anos, vem crescendo o número de gestantes adolescentes sem parceiro fixo ou sem companheiro. Alberto Olavo Reis afirma que, enquanto nos anos 70 e 80 - aqui no Brasil - a gestação na adolescência ocorria dentro do matrimonio e tinha um forte apelo moral e também legal para a responsabilidade do pai, hoje em dia, é comum ocorrer uma repetição, ou seja, uma nova gestação, na tentativa de fundar um laço matrimonial, na maioria das vezes, sem sucesso. $\mathrm{O}$ autor salienta que esse fenômeno é facilmente observável nas classes populares (Reis, 1998).

$\mathrm{O}$ “Acolhimento em grupo” para adolescentes não se constitui somente como uma reunião para triar adolescentes de acordo com o diagnóstico, a patologia ou a indicação terapêutica. Seu espaço é, acima de tudo, espaço de escuta, espaço aberto para o encontro e para a multiplicidade. A partir desses 
primeiros encontros, que denominamos de "acolhimento", o percurso de cada um pelo serviço vai se delineando, conforme suas necessidades. Por esse motivo, o serviço não se caracteriza pelo acesso específico aos(às) adolescentes envolvidos com a gravidez. Entretanto, muitos(as) adolescentes passam por essa experiência durante seu percurso nos atendimentos individuais ou em grupo.

Nossa preocupação no acolhimento é abrir um espaço para recebê-los, para conversar sem estabelecer uma utilidade para assuntos ou informações. Percebemos o quanto as iniciativas da saúde pública, no campo da orientação sexual para adolescentes e nos programas de planejamento familiar, se preocupam mais em informar do que ouvir ou dialogar com esses usuários. Muitas vezes, esse grupo etário é de difícil manejo, por isso, torna-se mais fácil aplicar o "kit informativo" do que produzir um trabalho local, respeitando as características do lugar, da população, a especificidade do grupo naquele tempo e naquele espaço particular. A posição que assumimos, no acolhimento em saúde mental para adolescentes, leva em conta esses aspectos, sendo nosso objetivo propiciar a troca de experiências, superando barreiras institucionais, burocracias da saúde pública, e iniciando reuniões em pequenos ou grandes grupos, com jovens acompanhados ou sozinhos, encaminhados ou “de passagem”.

A maior parte desses jovens é encaminhada, em geral, pelas equipes de atenção básica, por meio de um documento de referência e contrareferência ${ }^{7}$. Mas, além deste, os (as) jovens trazem outros documentos: das escolas, do Conselho Tutelar, do PEMSE (Programa Municipal de Execução de Medidas SocioEducativas), dos módulos da FASC, ${ }^{8}$ da FASE (antiga

7 Trata-se de um documento padronizado, no qual o profissional de saúde que encaminha (que faz a referência) se responsabiliza em identificar o problema, por meio de uma hipótese diagnóstica e o profissional (especialista) que recebe, deve informar, posteriormente, a evolução do tratamento, fazendo o mesmo documento retornar (contra-referência).

8 Antigamente, eram conhecidos como Centros de Convivência e mantidos pela Fundação de Educação Social Comunitária, atualmente Fundação de Assistência Social e Comunitária. 
Processos Psíquicos do Engravidamento na Adolescência em Contextos de Periferia

FEBEM) por meio dos documentos da JIJ (Juizado da Infância e da Juventude), do Ministério Público e suas promotorias.

A partir desses encaminhamentos, percebemos que grande parte desses documentos evidencia que as "referências" desses adolescentes são dadas pelas instituições de proteção e indicam contextos e problemáticas aparentemente bastante distantes da experiência gestacional. Na verdade, tal experiência tem maior visibilidade no campo da atenção primária e do que chamamos de saúde básica, uma vez em que envolve ações de prevenção, de promoção e de educação em saúde. Entretanto, é importante ressaltar que a prática psicológica em um serviço de saúde mental coletiva pressupõe um referencial e uma lógica pautados no modelo de atenção que preconiza abordagens preventivas, terapêuticas e curativas para o sofrimento psíquico. A abordagem de prevenção e de promoção em saúde mental coletiva, considerando o recorte específico da adolescência nos bairros populares, nesse sentido, deveria incluir, além do grande problema de saúde pública na juventude, que é o uso e abuso de substâncias psicoativas, os programas de educação em saúde reprodutiva.

Atualmente, como veremos mais adiante na análise documental, os Programas de Planejamento Familiar estão privilegiando, principalmente, a faixa entre 10 e 19 anos, já que as taxas de fecundidade têm aumentado nesse período. Cabe perguntar: quem são os atores desse programa? E quais deveriam ser os profissionais de saúde envolvidos nessa difícil tarefa? Sabemos que a Educação tem-se responsabilizado por essa temática, levando para a sala de aula discussões sobre a sexualidade, realizando grupos de orientação sexual, abordando a gestação na adolescência como eixo transversal dos Parâmetros Curriculares. Entretanto, colocamos em discussão, neste texto, o campo da saúde pública, por causa da necessária integração entre as ações das equipes de atenção básica e as ações das equipes de saúde mental, como coadjuvantes para a abordagem das questões constitutivas da sexualidade na adolescência e sua interface com os efeitos subjetivos da procriação, do exercício sexual, da erotização e das imbricadas condições anatômicas, morfológicas, maturacionais e de gênero. 
Quanto ao atendimento psicológico dos adolescentes, o processo de “engravidar” ocorre, para algumas adolescentes, durante seu percurso de tratamento, surgindo como um acontecimento, como um episódio sem relação com o motivo de consulta. E, realmente, parece demonstrar apenas um ponto em comum: o próprio processo da adolescência e o que ela traz de paradoxal, ou seja, a aceleração e a lentificação, a imediatez e a procrastinação (Jerusalinsky, 1997). Nesse sentido, o engravidamento e a experiência da gestação podem colar-se à aceleração biológica da transformação do corpo, ao mesmo tempo em que podem adiar algumas outras urgências, como a realização de um ideal social de independência, vinculada aos projetos profissionais e de educação escolar.

Cabe perguntar, nesse momento, qual seria a lógica e o sentido de uma gravidez entre jovens pobres do sexo feminino; e quais seriam as hipóteses das próprias jovens sobre esse "acontecimento” nas suas vidas. A questão central deste estudo pode ser assim expressa: qual a função subjetiva da possibilidade/impossibilidade de engravidar na adolescência?

E, considerando seu contexto social, essa questão tem muitos desdobramentos. Para essas jovens, que vivem em comunidades do meio urbanomarginal ou urbano-popular, a maternidade se constituiria ainda como único pilar para a valorização da identidade feminina? Além disso, nesses contextos, a passagem para a vida adulta se daria através da reprodução e a conseqüente formação de nova família e/ou constituição de novas unidades domésticas? Ou essas jovens poderiam esperar e se preparar para o seu ingresso no mercado de trabalho e construir um projeto de vida, cujo modelo de independência é o acesso a uma profissão?

\section{Descrição da atividade em grupo (“oficina de rap”)}

A abordagem terapêutica dos adolescentes no contexto da saúde mental coletiva deve priorizar o atendimento sistemático e continuado. Assim, os grupos terapêuticos, com encontros semanais, podem se constituir como uma alternativa eficaz para o tratamento, tanto quanto para a promoção da 
saúde mental e da saúde sexual reprodutiva, considerando a dimensão que a sexualidade ocupa no percurso da puberdade e da adolescência. A partir da puberdade, o sujeito adolescente passa a habitar um corpo sexualmente maduro com relação à aptidão reprodutiva e é convocado, pelo olhar de um semelhante do "outro sexo", a se apropriar de uma imagem do corpo transformada ${ }^{9}$.

As letras de Rap que analisamos mais adiante provieram de uma dessas experiências terapêuticas de grupo. O grupo terapêutico era formado por quatro rapazes e quatro garotas, entre 14 e 16 anos, e ocorria semanalmente no Centro de Saúde mencionado. No período de março a maio de 2004, montamos uma Oficina de Rap e o resultado nos surpreendeu, pois a escrita das garotas tematizou as formas singulares do seu envolvimento amoroso ${ }^{10}$, cotejando uma atividade sexual que poderia resultar em uma gravidez não esperada, enquanto a produção dos rapazes apresentou vivências relativas ao tráfico de drogas, uso de armas e violência na comunidade. A nossa sugestão foi de que cada um tentaria contar a sua história e transmitir a sua experiência, seguindo o modelo das produções de Rap que conheciam.

Jerusalinsky (1997) afirma que o “trauma” da adolescência é não ter uma posição para falar, já que a posição infantil deve ser abandonada e a posição de adulto não lhe compete. Entre “o ato” e "o brincar”, entre o “faz-deconta” infantil e o "ter-que-dar-conta” adulto, a adolescência torna-se o momento crucial para a construção de outros recursos para a elaboração psíquica.

Enquanto a criança cria um espaço de ilusão e uma distância necessária da realidade, através do brincar, o(a) adolescente tem de se virar com uma nova condição: ele(a) está jogado na realidade da existência do sexo e do desejo, porque a partir da puberdade fica mais difícil ignorar esses dese-

9 Para Rassial (1997), trata-se da recapitulação, na adolescência, do estádio do espelho.

10 Esse envolvimento, dito amoroso, aparece caracterizado como "paixão" nas letras produzidas pelas meninas. 
jos que sempre existiram ${ }^{11}$. A virada da puberdade é a assunção de um desejo, que é sexual e passa a recapitular as experiências infantis, traduzindo o enigma da atividade-passividade, uma vez que a passividade infantil seria a conseqüência do não engajamento de um desejo que o sujeito possa supor na cena (Corso, 2004).

Para as adolescentes deste estudo, percebemos que esse outro recurso de elaboração psíquica partiu de um eixo ficcional: escrever e narrar uma história a partir de uma experiência vivida. O tempo para escrever e o espaço para contar produziu um efeito de implicação subjetiva, porque aconteceu dentro de um grupo, e refletiu um "contar-se” para os outros, que busca encontrar significação para a diferença sexual e, também, produzir laços de sustentação entre a adolescente e seu lugar na feminilidade.

Retomando os objetivos deste artigo, queremos enfatizar a importância desses processos de "fabulação"12 e de simbolização entre as adolescentes, os quais, justamente, escapam e se furtam diante das nossas tentativas e preocupações em "informar" e estabelecer normas e cuidados para a saúde sexual reprodutiva. Para isso, precisamos escutar e deixar emergir a fala dessas jovens.

\section{O que dizem as letras de Rap de três adolescentes}

Na “oficina de Rap” realizada em um grupo terapêutico, entre os meses de março e maio de 2004, as adolescentes Ane, Larissa e Vanessa ${ }^{13}$ apresentaram as seguintes produções escritas, que optamos por reproduzir integralmente, antes de demonstrarmos os resultados da análise de conteúdo.

11 Para Birman (1999), a novidade da teoria psicanalítica sobre a incidência do sexual, a partir da obra de Freud, é a sua abordagem desde a infância.

12 Utilizamos esse termo para enfatizar a construção de narrativas ficcionais. Chemama (2002) define o termo ficção como estando para além do erro ou da exatidão: seria "toda construção linguageira pela qual, de maneira mais ou menos direta e mais ou menos manifesta, tentamos suturar a hiância sexual” (p. 295).

13 Trata-se de nomes fictícios para que a identidade das adolescentes seja preservada. 
Após cada letra, procuramos situar três pontos de referência, os quais, a nosso ver, amparam suas narrativas e também seu percurso no atendimento. Primeiro, seu contexto sociofamiliar; segundo, o motivo de consulta; e terceiro, os efeitos subjetivos do atendimento em grupo: experiência, identificação e transferência.

- $\quad$ Ane (16 anos completos):

Eu vou falar/ agora eu vou falar/ Eu sou mulher e vim aqui para falar que o filho que eu fiz, eu fiz sem pensar/ Eu era tão novinha, não entendia nada/ Agora que eu vi, eu entrei numa roubada. Mulheres da Vila ${ }^{14}$, estão aqui para falar: use camisinha, vamos se ligar/ Mulheres inteligentes precisam se cuidar. / É isso aí mulherada, vamos se unir! / Vamos mostrar para os manos que a inteligência tá aqui! Aqui na Vila, só falamos a verdade/ O que acontece aqui é a mais pura realidade. Preste atenção, porque eu não vou mentir/ Quem está falando agora é as manas MCs.

O contexto familiar de Ane inclui histórias e experiências vertiginosas de relacionamentos conturbados entre ela e sua mãe e, também, entre sua mãe e diferentes parceiros. Desamparo e abandono, coabitações e mudanças dramáticas de lugar, além da necessidade de elaborar o luto pela perda da avó, que, precisamente, teria sido a figura de maior permanência na sua infância, constituem o pano de fundo das suas cenas de vida. Além disso, sua trajetória assemelha-se a de qualquer outro(a) jovem de periferia: a necessidade de aceitar diferentes “padrastos” e novas configurações familiares, com meio-irmãos, irmãos emprestados, irmãos de sangue, numa seqüência de interações entre fratrias que vai do espaço familiar ao espaço coletivo - irmãos de religião, irmãos de cor e de raça, irmãos da “vila”, enfim, “os manos” e “as manas”, a propósito da filosofia e do estilo introduzido pelo RAP.

O motivo que gerou seu encaminhamento ao serviço de acolhimento para adolescentes foi uma passagem ao ato, quando Ane agrediu fisicamente uma professora na escola, por esta ter-se referido à cor da sua pele de forma

14 Substituímos o nome da comunidade, citado na letra duas vezes, por "vila”, para garantir o anonimato. 
pejorativa. A cena é deslocada do ambiente familiar, no qual vive uma relação de hostilidade com a mãe e o padrasto, mas também dá a ver sua "atitude" como procedente desse estilo mencionado acima, que preconiza, por meio dos diferentes grupos de rap, o orgulho de ser "preto", o orgulho da“raça” e o fim da humildade (do sentimento de inferioridade). Dessa forma, "encarar” o desrespeito "burguês" e, se necessário, "revidar", 15 pode ser importante.

Para muitos adolescentes de periferia, a experiência do Rap vem ao encontro de uma necessidade legítima de constituir "uma irmandade", de fundar uma "fratria”. O Rap parece responder a essa demanda, a esse pedido de uma identidade coletiva, ao mesmo tempo em que convoca o ouvinte a fazer parte e, portanto, a se identificar. O Rap produz histórias que Ane conhece muito de perto, no lugar onde mora. Mas o que Ane extraiu do Rap foi um outro tipo de protesto, um outro tipo de manifesto, que é mais específico da feminilidade, porque fala de uma experiência corriqueira das "mulheres da Vila” e porque, principalmente, fala da sua experiência.

Durante o atendimento e no momento dessa produção escrita, Ane tinha provocado um aborto usando um medicamento (cytotec) ${ }^{16}$; entretanto, na letra de rap que trouxe para o grupo, Ane "fala” de um filho feito sem pensar e não de ter engravidado “sem querer”. Essa passagem é importante porque o percurso que levou a paciente a esse aborto provocado teve origem numa relação de espelhamento com sua prima.

Exatamente nesse período, Ane estava morando com uma tia materna e estudava, na escola, com uma de suas primas. O centro de sua identificação passou pela experiência da prima mais velha, que engravidou e usou esse mesmo medicamento. A história contada pela paciente é trágica: sua

15 As palavras entre aspas nesse parágrafo foram destacadas porque aparecem em algumas letras de rap do grupo Racionais (grupo paulista composto por Mano Brown, Ice Blue, K.L. Jay e Edy Rock), segundo destaca M. R. Kehl (2000).

16 Cytotec é um medicamento indicado para prevenção e tratamento de úlceras gástricas e foi lançado no Brasil em 1984. É usado ilegalmente como abortivo porque provoca fortes contrações no útero, deslocando a placenta. Em 1998, o Ministério da Saúde restringiu a venda do produto; entretanto, há um comércio ilegal e de fácil acesso nas comunidades de periferia. 
Processos Psíquicos do Engravidamento na Adolescência em Contextos de Periferia

prima introduziu os comprimidos no canal vaginal quando estava no terceiro mês de gestação. Houve um sangramento e ela pensou que tinha dado certo, mas enganou-se: passados outros três meses, sua prima teve parto prematuro e “o bebê que nasceu estava morto”, segundo relatou a paciente.

Além dessa história, outras experiências vão sendo relatadas e percebemos o quanto há de um saber feminino, que se transmite e compõe os traços possíveis de filiação, fratria e pertencimento entre Ane e suas "primas": "as Manas”. Não tardou para que ela revelasse sua própria experiência.

No texto "Psicologia das Massas e Análise do Eu”, Freud (1920/1981) apresenta a noção de "sintoma compartilhado", que fornece a base das identificações histéricas nas instituições para moças, no século XIX e início do século XX. Ele situa três fontes para constituir o processo de identificação: primeiro, o processo mais original e primitivo da identificação, ou seja, a identificação como "laço emocional”; segundo, como vinculação de objeto libidinal através da introjeção do objeto no ego; e terceiro, como percepção de uma "qualidade comum partilhada” com uma pessoa que não é objeto da pulsão sexual. Dessa forma, o tipo de laço existente entre os membros de um grupo, como no caso das moças em um internato, forneceria reforço narcísico para cada uma e para o grupo, assim como referenciais para as identificações imaginárias mútuas.

Identificações e ideais vinculam o sujeito ao grupo (amigos, familiares, colegas), inserindo-o na cena social. Esse seria o desafio para o sujeito adolescente, o de criar e estabelecer vínculos e contatos. Tomando a perspectiva de Rassial (1997) para o conceito de reprodução sexual, é fundamental dar visibilidade ao contexto geracional e intergeracional, cultural e comunitário dessas adolescentes, uma vez que convocam para uma relação de espelhamento, de identificações parciais e montagem de traços identitários compartilhados. É a partir da feminilidade e dos contextos de transmissão de saber (um saber feminino) que uma adolescente vai implicar-se ou não na maternidade; vai suportar ou não uma gravidez na sua vida.

- $\quad$ Larissa (14 anos incompletos): 
Eu tava na esquina beijando meu namorado. Foi quando eu olhei e vi que era errado. E ele disse que me amava e eu acreditei. Me chamaram de bobinha, mais um sonho que eu errei. O pensamento era longe. E era só nisso que eu pensava. E nada mais me importava. E a minha cabeça virava, meu coração amolentava e o desejo aumentava.

Não sei o que fazer meu irmão: me dê uma dica, me dê uma sugestão! / Não sei o que fazer. Não sei se vou morrer. / Não tenho muitos amigos e tenho medo de sofrer. / Pra mim, naquele tempo era só amor que restava, nada mais importava. / Não sei o que fazer, sou uma menina ingênua: meus olhos dizem sim e minha boca diz não, como posso saber o que diz meu coração.

Para introduzir o percurso clínico de Larissa, começaremos com uma história. Nosso objetivo é ilustrar as cenas familiares e destacar o lugar que ocupa um imperativo materno quando, a propósito da puberdade, surgem os “comentários” que acompanham as primeiras "regras”, ou melhor, a menarca.

Trata-se de um fragmento apresentado pela psicanalista Jane Wiltord, no Seminário de Bergès (Bergès \& Balbo, 2003), sobre um povoado na Martinica, ilha de colonização francesa na América Central, em que a mãe diz para sua filha púbere a seguinte frase, quando esta quer sair de casa,: "eu não quero que você traga uma criança para mim”. Jane Wiltord (citado por Bergès \& Balbo, 2003) salienta que essa frase tem um duplo sentido na forma como é enunciada, devido ao dialeto local. O outro sentido seria: "eu não quero que você fale com um homem”.

Jean Bergès (Bergès \& Balbo, 2003) refere que esse enunciado denegatório da mãe funda a hipótese de uma demanda para a filha, porque afirma a existência ou a possibilidade de advir uma criança. Essa demanda, suposta pela filha, seria relativa a um desejo da sua mãe de que ela procriasse, intervindo, imediatamente, na relação entre mãe e filha, desde que essa última está iniciando o ciclo menstrual. Essa hipótese da filha implica um saber que está suposto na linhagem e que é desconhecido. Para o autor, a mãe passa a ocupar um outro lugar na linhagem: "ela não lhe fala como mãe, ela lhe fala como futura avó” (Bergès \& Balbo 2003, p. 79). Assim, é importante desta- 
Processos Psíquicos do Engravidamento na Adolescência em Contextos de Periferia

car a diferença entre linhagem e filiação, porque enquanto uma é ascendente, a outra é descendente.

Bergès (Bergès \& Balbo, 2003) escreve:

Se a linhagem é caracterizada pelo fato de sentir o corpo imaginário de seus ancestrais no seu próprio corpo (...), o desconhecimento desse saber nas articulações com o imaginário do corpo, e os efeitos que persistem da teoria sexual infantil, podem levar bem longe. (p. 86)

E, realmente, levam muitas adolescentes longe com relação às possibilidades, ensaios e experiências que vão fazer até se apropriarem do funcionamento reprodutivo do próprio corpo e verificarem alguma realidade sobre os mandatos e previsões feitos na família e no entorno.

O motivo do encaminhamento e da chegada de Larissa foi um desentendimento com sua tia que denunciou para sua mãe um namoro proibido. Larissa estava mantendo um relacionamento amoroso com um rapaz mais velho, longe dos olhos da mãe e dos familiares, entretanto, fora surpreendida por essa tia delatante, que, imediatamente, constatou a possibilidade do exercício sexual, apesar de a paciente dizer-se “ainda virgem”.

Seu contexto familiar é complexo: separação dos pais e pouco contato com seu pai; história de quadros depressivos na linhagem materna: avô materno alcoólatra, tia materna com tentativa de suicídio e sua mãe, que fazia uso de antidepressivos. Esses traços familiares podem produzir identificações parciais e, considerando a passagem pela adolescência conjugada ao envolvimento amoroso, podem reativar a posição depressiva, tendo em vista que o objeto amoroso é sempre suscetível de ser perdido.

Kristeva (2002) salienta que o imaginário adolescente é essencialmente amoroso e, através da atividade de escrita, pode retomar o processo de simbolização e de elaboração fantasmática, permitindo um ajustamento das pulsões e dos signos, através dos códigos imaginários disponíveis. $\mathrm{O}$ adolescente seria uma estrutura psíquica aberta ao recalcado, portanto, precisaria repor suas identificações, suas capacidades de palavra e de simbolização, pa- 
ra elaborar um discurso e uma narrativa que possam integrar os eventos psíquicos. A escrita, na adolescência, faria essa função.

A experiência de Larissa, que não está aparente nesse escrito que produziu, refere-se ao medo de engravidar. Quando começou a participar do grupo, contou - em sigilo - que não era mais virgem e ninguém na sua família poderia saber. No decorrer do seu atendimento, houve episódios de atraso menstrual e de desespero quanto à possibilidade de uma gravidez, que a fizeram procurar procedimentos que lhe garantissem um "não-engravidamento”, como a pílula do dia seguinte ${ }^{17}$.

Essas situações “embaraçosas” ocorriam, em geral, nos finais-desemana, quando ela não podia procurar ajuda no grupo ou no atendimento individual. Por isso, sua escrita aparece como um pedido incessante de ajuda, ao mesmo tempo em que, paradoxalmente, percebemos que a possibilidade do engravidamento ocorre sempre na impossibilidade de pedir ajuda, da mesma forma que sua atuação demonstra uma antecipação relativa a estar grávida e não uma atitude de prevenção para não engravidar.

- Vanessa (15 anos incompletos):

Minha vida é complicada. Não posso fazer nada./ Sou muito rejeitada e já fui até saco de pancada./ Fazia tudo o que não podia e pensava que ia dar em alegria./ Mas percebi que era só ilusão./ No começo era só curtição: na hora ia tudo pra mente e todo mundo parecia diferente. Quando acabava parecia ser o fim./ O fim do mundo? Não, mas sim o meu fim./

Na escola não fazia nada./ Larguei meus amigos de mão, por causa de uma paixão, que não tinha razão./ Hoje podia estar grávida, mas Deus me iluminou e o exame disse não.

17 Trata-se da pílula anticoncepcional de emergência, recurso que pode ser usado após uma relação sexual desprotegida para evitar gravidez indesejada. Deve ser usada até 72 horas após a relação. Quanto mais cedo for usada, tanto maior a sua eficácia. Não deve ser utilizada de rotina como método anticoncepcional. Não interrompe uma gravidez em andamento. Não protege contra DST/HIV/AIDS. 
Processos Psíquicos do Engravidamento na Adolescência em Contextos de Periferia

Pode crê, foi tudo ilusão. Olho meu passado e vejo os irmão atirado no chão e viciado nas drogas./ Mano, eu saí dessa vida torta.

Vanessa evidencia, na sua escrita, o motivo de estar em tratamento. Ela estava usando drogas. Entretanto, essa experiência demonstrou ser o menor entre os motivos.

Aos 12 anos, teve um relacionamento precoce: sua mãe permitiu que seu namorado morasse na sua casa e, após 2 anos, quando se separaram, ela estava grávida. Esse convívio entre eles, ambos usando drogas, resultou em fortes paixões: violência, brigas e agressões. Quando engravidou, parecia ter recuperado o vínculo perdido com a separação, mas ocorreu um aborto espontâneo, possivelmente devido ao uso de substâncias psicoativas.

Seu contexto familiar é o seguinte: mora com avó materna, sua mãe e uma irmã - filha de outro pai. Um dado interessante é que sua mãe tinha 15 anos quando engravidou pela primeira vez e nunca manteve um relacionamento conjugal, nem quando engravidou a segunda vez, ocasião do nascimento de Vanessa. Por isso, a paciente não conheceu o pai.

Sobre essa paciente, queremos salientar a sobreposição de duas problemáticas: a ausência da figura masculina para a mãe e de um referencial paterno para a filha. Assim, a adolescência de Vanessa denota a impossibilidade da elaboração do lugar do pai.

Rassial (1997) constrói a noção de "passagem” na adolescência, que põe à prova a estruturação psíquica. Esse processo tem a ver com a necessidade, para qualquer adolescente, de realizar, a posteriori, uma série de operações fundadoras do desenvolvimento emocional infantil, constituindo, dessa forma, um trabalho psíquico.

Examinemos, brevemente, a posição freudiana (Freud, 1905/1981), a qual nos dará indícios de que os processos anteriores, vividos na infância, devem ser reordenados pela adolescência, dando ênfase à sexualidade e ao desligamento das figuras parentais. O destaque é dado às fantasias incestuosas que ressurgem, agora fortificadas pela energia somática, gerando um impasse que leva o jovem ao desligamento dos pais. Todavia é essa inclinação 
infantil até os pais, que, renovada na puberdade, marcará o caminho para a eleição de objeto.

Então, estamos falando de três reedições: a reedição da fase do espelho, no qual a constituição imaginária do eu se ancora pela presença do outro; a reedição do Édipo, enquanto caminho para a eleição de objeto e o impasse do desligamento dos pais com o desmoronamento da consistência parental imaginária do Outro. Assim, novamente com Rassial (1997), veremos que o Outro e o objeto adquirem um novo valor psíquico na adolescência, a saber: enquanto o Outro do lactente deve ser referido à mãe e o Outro do Édipo aos pais, o Outro do adolescente está, imaginariamente, ligado ao Outro sexo.

No caso de Vanessa, há um pedido impossível: de que o Outro sexo venha cumprir uma função paterna e, assim, através de uma presença real, possa produzir uma consistência simbólica. O efeito dessa operação aparece nas tentativas malsucedidas de engravidar, nas quais o "medo/desejo de poder engravidar” e o “medo/desejo de não poder engravidar” se equivalem.

\section{A Análise de Conteúdo}

As categorias descritas a seguir emergiram dos conteúdos das letras escritas e foram sugestões dos participantes do grupo, constituindo, portanto, suas próprias falas:

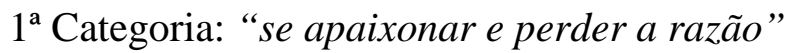

Paixão e excitação sexual. No momento da paixão, todo pensamento racional, todo planejamento, deixa de ter importância. Estar apaixonada é como entrar numa roubada, escolher acreditar em ilusões, em sonhos e em devaneios, ser levada pelo desejo (sexual) e, principalmente, perceber-se ativa na intenção de tornar-se desejável e de desejar, provocar o olhar do outro e, então, deixar de enxergar o que é certo ou errado.

A: "Eu era tão novinha, não entendia nada. Agora que eu vi, eu entrei numa roubada." 
L: "Eu tava na esquina beijando meu namorado. Foi quando eu olhei e vi que era errado. E ele disse que me amava e eu acreditei. Me chamaram de bobinha, mais um sonho que eu errei. O pensamento era longe. E era só nisso que eu pensava. E nada mais me importava. E a minha cabeça virava, meu coração amolentava e o desejo aumentava."

V: "Fazia tudo o que não podia e pensava que ia dar em alegria./ Mas percebi que era só ilusão. (...) Larguei meus amigos de mão, por causa de uma paixão, que não tinha razão.”

2 Categoria: “engravidar" e "não saber o que fazer"

A categoria faz emergir um impasse entre a antecipação relativa a estar grávida e as condições de prevenção para não engravidar. Trata-se de um paradoxo que explicita um comportamento adolescente de não-prevenção frente à possibilidade de engravidar e uma atuação relativa a ter que fazer algo a posteriori.

A: "Eu sou mulher e vim aqui para falar que o filho que eu fiz, eu fiz sem pensar. Eu era tão novinha, não entendia nada. Agora que eu vi, eu entrei numa roubada."

L: "Não sei o que fazer meu irmão: me dê uma dica, me dê uma sugestão! Não sei o que fazer. Não sei se vou morrer. Não tenho muitos amigos e tenho medo de sofrer.”

V: "Hoje podia estar grávida, mas Deus me iluminou e o exame disse não. Pode crê foi tudo ilusão.”

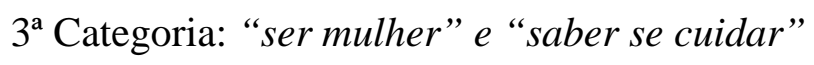

As adolescentes querem encontrar um lugar desde o qual possam falar. Não se trata de qualquer lugar, mas de um lugar de referência feminino, um lugar de "mulher", que possa, ao mesmo tempo, efetivar a passagem entre a infância e a fase adulta; um lugar de sujeito que reconhece e se posiciona perante o passado. É como se recuperassem a razão e a inteligência, a ca- 
pacidade de pensar, a capacidade de se cuidar e escolher seu destino, sem ilusões.

A: "Eu sou mulher e vim aqui para falar (...) Mulheres da Vila, estão aqui para falar: use camisinha, vamos se ligar/ Mulheres inteligentes precisam se cuidar. / É isso aí mulherada, vamos se unir! Vamos mostrar para os manos que a inteligência tá aqui! Aqui na Vila, só falamos a verdade/ O que acontece aqui é a mais pura realidade.”

L: “Pra mim, naquele tempo era só amor que restava, nada mais importava.”

V: "Pode crê foi tudo ilusão. Olho meu passado e vejo os irmão atirado no chão e viciado nas drogas./ Mano, eu saí dessa vida torta.”

\section{Uma revisão de documentos sobre saúde sexual reprodutiva}

Na rede de atenção primária, as equipes de saúde utilizam materiais informativos e manuais estabelecidos pelo Ministério de Saúde. Selecionamos alguns trechos que nos pareceram mais relevantes para este estudo e que trataremos de analisar a seguir.

Assim, citaremos as orientações quanto à saúde sexual e reprodutiva dos adolescentes, as quais constam no material de distribuição exclusiva às Unidades de Saúde, com o título "Assistência em Planejamento Familiar: Manual Técnico” e que trata, no seu capítulo 9, da “Anticoncepção na adolescência”.

\section{O Documento}

O elevado número de partos entre as adolescentes, o início cada vez mais precoce das relações sexuais e o aumento das DST/AIDS nessa faixa etária justificam a prestação de uma assistência adequada às necessidades da população na faixa etária de 10 a 19 anos.(...) 
Processos Psíquicos do Engravidamento na Adolescência em Contextos de Periferia

A qualidade desta atenção pressupõe minimamente: boa comunicação; confidencialidade, privacidade, disponibilidade constante de insumos para a dupla proteção; (...) atenção especial as faixas etárias mais precoces (10 a 14 anos) quando na região se registra um aumento de gestação nessa faixa etária; a avaliação integral do(a) adolescente incluirá a avaliação psicossocial, além do exame físico; os/as adolescentes são o centro de interesse na entrevista e os pais e familiares só estarão presentes se ele ou ela permitir.

Recomenda-se trabalhar ações educativas de prevenção nas unidades de saúde, escola, centro de lazer, centro esportivo ou cultural entre outros.(Ministério da Saúde, 2002, p. 126)

Os adolescentes podem utilizar qualquer método anticoncepcional desde que não apresentem alguma das condições clínicas que contra-indiquem seu uso, conforme critérios de elegibilidade descritos para cada método. (Ministério da Saúde, 2002, p. 129)

\section{A Análise de Conteúdo}

Os procedimentos que adotamos para a análise de conteúdo desse documento incluem três passos: a leitura flutuante, a marcação de transições de significado e a interpretação através de categorias emergentes (Bardin, 1977).

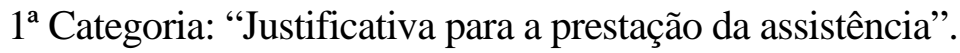

Essa categoria pode se desdobrar em duas subcategorias: “o aumento” e a "precocidade”. Com relação à primeira, parece evidenciar uma contradição entre a concepção do que seria "prevenção” e a necessidade de dar visibilidade ao tema, por meio do "elevado número" ou do que seria o "aumento” do problema. Se o objetivo é prevenção, os programas e ações devem ser desenvolvidos independentemente do maior ou menor registro de casos.

O elevado número de partos entre as adolescentes, e o aumento das DST/AIDS (...) quando na região se registra um aumento de gestação nessa faixa etária (...) 
Recomenda-se trabalhar ações educativas de prevenção nas unidades de saúde, escola, centro de lazer, centro esportivo ou cultural entre outros (...) (Ministério da Saúde, 2002, p. 126)

Com relação à segunda subcategoria, aparecem explicações que determinam o que seria considerado precoce, e quando. Entre 10 e 14 anos, as relações sexuais são precoces.

(...) o início cada vez mais precoce das relações sexuais (...) atenção especial às faixas etárias mais precoces (10 a 14 anos). (Ministério da Saúde, 2002, p. 126)

2 Categoria: “A relação entre partos e contaminação pelo HIV”.

O elevado número de partos entre as adolescentes, (...) e o aumento das DST/AIDS nessa faixa etária (...) (Ministério da Saúde, 2002, p. 126)

A produção atual de conhecimento sobre o "mal do século”, sobre uma doença, até pouco tempo, dita incurável (AIDS), nos fez perceber o quanto o uso de preservativo (conhecido como "Camisa de Vênus") esteve por muito tempo associado à anticoncepção, ou seja, visto como mais um método anticonceptivo e, portanto, condenável aos olhos da Igreja, e servindo mais ao controle da natalidade do que ao essencial controle das doenças sexualmente transmissíveis (DSTs). Basta lembrar o quanto as pessoas se viram alarmadas em descobrir a necessidade do uso desse dispositivo também na prática do sexo oral, considerando a forma imperceptível do HIV comparado às DSTs.

Então, por um lado, constata-se a demora para a conscientização sobre o uso de preservativos como dispositivo plenamente eficaz para evitar a transmissão e o contágio de doenças sexuais, pois a lógica era mais ou menos como a que ouvi um adolescente dizer em um grupo: "se quero evitar filhos, transo com camisinha” e "se quero evitar doenças, não transo com doente”. É importante ressaltar que o “condom” é uma espécie de anticoncepcional masculino, pois vemos a esfera da decisão sobre seu uso depender das condições masculinas. Uma mudança nessa lógica ocorreu, dadas as características insidiosas do HIV, tais como: a dificuldade para identificar o 
portador ou para identificar-se como soropositivo; o longo período de incubação, sem manifestações sintomáticas; o período de janela imunológica; o acesso aos recursos para testagem e retestagem.

Por outro lado, vemos novamente surgir o mesmo equívoco, quando usamos o argumento da proteção contra as doenças e, na verdade, queremos evitar a gestação precoce. Assim, falamos em sexo protegido ou em sexo seguro, para salientar que o uso de preservativos impediu e impede a disseminação da AIDS, mas vemos o quanto esse argumento serve para indiciarmos os jovens como os grandes culpados de estarem contraindo doenças e "gestações".

A atividade sexual que resulta em gravidez supõe que os sujeitos envolvidos não cumpriram as determinações do tão aclamado "sexo seguro", então, a estratégia para prestar assistência e disponibilizar informação é alarmista. Podemos explicitar a confusão entre o nascimento de uma criança e a possibilidade do contágio de uma doença letal.

Um programa de prevenção destinado aos adolescentes não deveria confundir as possibilidades de engravidar e de gerar um filho com a contaminação de um vírus. Tal orientação, tão importante, deveria tão-somente trabalhar a escuta a partir do enigma da procriação (das fantasias e ficções infantis que retornam na puberdade), esvaziado por conteúdos nefastos como esse, relativo ao HIV.

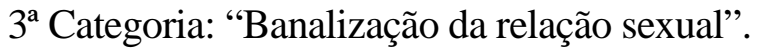

O documento dá a entender que, se houver insumos para a dupla proteção, para que os adolescentes façam uso de qualquer método anticonceptivo, então, os objetivos serão atingidos, uma vez que o mais importante é prevenir a contaminação pelas DST/AIDS e a gravidez.

(...) disponibilidade constante de insumos para a dupla proteção (Ministério da Saúde, 2002, p. 126) 
(...) Os adolescentes podem utilizar qualquer método anticoncepcional (Ministério da Saúde, 2002, p. 129)

Precisamos estar atentos sobre o lugar contemporâneo do saber, visto que esse saber sobre a sexualidade constituiu um lugar "higienista". Na concepção de Rassial (2004), esse paradigma higienista na relação sexual produz um ideal de apaziguamento pela morte do outro, ou melhor, na relação ao outro sexo. Essa pacificação que higieniza aparece como realização da pulsão de morte e, portanto, como lugar de gozo.

O que encontramos como patologia sexual na periferia e que se propaga numa banalização acentuada pela mídia? O autor vai responder que encontramos os estupros, as violações, os abusos e a violência sexual.

Rassial (2004) cita, como exemplo, a experiência do "tournante” (p. 291), na França: uma espécie de estupro coletivo, em que um jovem seduz uma moça e a partilha com seus parceiros. O autor refere que já é possível se estimar em $20 \%$ o número de meninas que têm sua primeira relação sexual desse modo. A resposta dos jovens é a seguinte: "nós sempre usamos preservativos”. Dessa forma, evidenciam-se duas operações contraditórias: por um lado, a presença que testemunha a realização de um ato sexual, ou que compartilharia a impotência, e, por outro, “a negação do ato sexual”, pois o preservativo pode proteger de tudo, até mesmo do amor (p. 292). A impotência está na impossibilidade de uma realização coletiva do falo, entretanto, o desinvestimento do caráter "sexual" do ato e a convocação de testemunhos supõem a possibilidade dessa realização, efetivando a disjunção entre sexo, amor e intimidade.

\section{Comentários finais}

A título de conclusão, recapitulamos algumas noções investigadas por nós, a partir dessa temática: a noção de engravidamento e os processos singulares de elaboração psíquica na adolescência; o contexto intergeracional e 
a forma como os trabalhadores e técnicos de saúde pública comunicam e informam os(as) adolescentes sobre saúde sexual e reprodutiva.

Por um lado, apresentamos a hipótese de que as possibilidades do engravidar na adolescência articulam-se aos modos singulares de viver essa passagem. Ou seja, consideramos que os processos subjetivos de construção e representação da feminilidade em contextos de periferia, que incluem a menarca e o início da atividade sexual, são determinantes para a noção de engravidamento.

Há uma decalagem entre “engravidar” e "tornar-se grávida”. O termo engravidamento foi adotado neste trabalho para enfatizar o processo de implicação subjetiva de uma adolescente diante da "possibilidade” de tornar-se grávida. Exploramos a contingência dessa situação da seguinte forma: inicia-se com a suposição de estar grávida (suposição que revela uma expectativa de dar conta de um corpo sexuado feminino), persiste enquanto possibilidade ou dúvida e aguarda/espera sua confirmação ou certeza. Ou melhor, há uma passagem de tempo entre as mudanças provocadas pela irrupção da puberdade e o processo subjetivo de apropriação de um corpo de mulher “terminado”, a partir das primeiras relações sexuais.

Assim, entre o corpo "contingente"18 e em transformação de uma adolescente e o corpo de mulher, os ensaios e experiências sexuais surgem para testar/confirmar essas novas potências. Dessa forma, identificamos intervalos temporais para o processo de engravidamento na adolescência, a partir da noção lacaniana de tempo lógico (Lacan, 1966/ 1978), no qual o instante do ato sexual (sem a utilização de métodos anticoncepcionais) dá início à implicação subjetiva com esse ato, através da dúvida (estar ou não estar grá-

18 A contingência do corpo em transformação e os aspectos defendidos pela teoria psicanalítica relativos ao abandono do corpo infantil. A metáfora do "complexo da lagosta”, usada por Dolto e Dolto-Tolitch (1993), expressa a perda de referências físicas e o estado de fragilidade que o processo adolescente impõe ao púbere, o qual seria análogo ao do crustáceo, quando este perde a sua carcaça para crescer, passando a ficar sem defesas e exposto aos perigos de predadores, até que seu organismo produza uma nova proteção, adequada para seu tamanho. 
vida), passando por um tempo de espera e de cogitação (“fiz, logo estou”), até a certeza antecipada que instaura a asserção subjetiva.

Identificamos, entre as categorias de análise encontradas nas letras de Rap das adolescentes, esses três tempos da seguinte forma: "se apaixonar $e$ perder a razão" como um "instante de ver”; "engravidar e não saber o que fazer" como o "tempo de compreender"; e "ser mulher e saber se cuidar" como o "momento de concluir”. Para Lacan (1966/1978), o sofisma dos três tempos lógicos indica as condições de subjetivação da seguinte forma: sujeito impessoal para o instante de ver; sujeito indefinido recíproco para o tempo de compreender e o sujeito da asserção para o momento de concluir.

Por outro lado, demonstramos que o convívio entre gerações, a linhagem familiar e a filiação tomam um lugar privilegiado para refletirmos sobre a transmissão dos traços familiares que constitui a geração de um filho, tornando visível a dimensão coletiva e cultural dessa experiência. O que implica dizer que o processo de engravidamento é vivido de forma singular, mas vem dar conta de um laço coletivo e de uma herança intergeracional. Assim, buscamos evidenciar a pouca eficácia no investimento de programas voltados à saúde sexual, que não respeitem esses aspectos.

Além disso, podemos observar que os processos de simbolização e de construção ficcional das adolescentes escapam e também são negados, quando as tentativas e preocupações de "informar" e estabelecer normas e cuidados para a saúde sexual reprodutiva (ex. manuais e livretos educativos) são mais importantes. Antes de produzirmos materiais informativos e recursos que sirvam para todas as adolescentes, há que se poder responder como uma adolescente antecipa a possibilidade de engravidar, levando em conta o contexto social e geracional, e que significações são produzidas, justificando sua experiência sexual.

Por exemplo, se retomarmos os processos psíquicos que investigamos em cada história, perceberemos o enlace de três aspectos: os processos identificatórios (espelhamento, identificações parciais, traços identitários compartilhados); o imaginário “amoroso” adolescente, reativando a posição depressiva (Kristeva, 2002); e a elaboração do lugar do pai como função simbólica. 
Esse enlace tem a ver com a dimensão temporal, a qual é inerente à ação do simbólico: o “só depois”, relativo à temporalidade dos processos inconscientes (ou seja, entre a experiência ou traço mnêmico e a sua representação), explicita o paradoxo da condição adolescente, ou melhor, quando a precipitação toma o lugar da prevenção e, a antecipação, o lugar da verificação. A pressa em fazer algo, assim como demonstramos no caso de Larissa e também de Ane, podemos, por ora, traduzir como esse efeito simbólico de ter "entrado numa roubada" e ter de compensar, fazendo algo a posteriori e produzindo um elo entre a subjetividade antecipada (ter engravidado) e a possibilidade resguardada do vir-a-ser (engravidar), em um outro tempo.

Para concluir, esperamos que este trabalho possa contribuir para incrementar o debate em torno dessa temática, sem esquecermos do nosso compromisso com as ações concretas desenvolvidas no âmbito da saúde. Portanto, nesse sentido, pensamos ter contribuído também para problematizar a nossa visão de "saúde do adolescente", abrindo eixos de integração entre programas e políticas (saúde do escolar, saúde mental, saúde básica, saúde sexual e reprodutiva) e ampliando as noções de "prevenção” e de "saúde” para compor parcerias intersetoriais com a assistência social, cultura e educação.

Loss, M. A., \& Sapiro, C. M. (2005). Psychological process of getting pregnant in adolescence in a poor community: impasses and possibilities. Psicologia USP, 16 (4), 69-98.

\begin{abstract}
This study presents the partial results of a content analysis of group sessions involving adolescents in a public ambulatory of Porto Alegre, RS. Our goal was to investigate female adolescents who live in a poor neighborhood of Porto Alegre, in their psychological processes of anticipating the possibilities of getting pregnant. Data collection consisted of "rap" verses written by the adolescents participants in 10 group sessions, as well as the excerpts of technical and educational manuals of sexual health and reproductive sex that constitute work tools in Public Health. The emergent categories of a content analysis revealed the inadequacy and the gap between the adolescents language and culture and the content of the
\end{abstract}




\section{Maria Aparecida Loss e Clary M. Sapiro}

material implemented as instructive and educational. We emphasize the subjective and unconscious aspects that involve human reproduction, by suggesting the neologism "engravidamento" ("pregnanting”) as a psychological process in adolescence.

Index terms: Adolescent pregnancy. Female sexuality. Psychotherapeutic processes.

Loss, M. A., \& Sapiro, C. M. (2005). Processus psychologique de l' enceintement (devenir enceinte) à l'adolescence dans une communauté pauvre: impasses et possibilités. Psicologia USP, 16 (4), 69-98.

Résumé : Cet étude présente les résultats partiels d'une analyse de contenu réalisée dans de sessions en groupe formée par adolescents dans un poste de secours public à Porto Alegre, RS. Notre but était enquêter des adolescents féminins qui habitent dans un banlieue pauvre de Porto Alegre, dans leurs processus psychologiques d'anticiper les possibilités de devenir enceinte. Les données recueillis ont consistés de "vers de rap (style de musique)" écrits par les adolescents qui participaient dans 10 sessions en groupe, aussi bien que les fragments (extraits) d'un manuel technique et pédagogique de santé sexuelle et de reproduction qui est un outil de travail dans la Santé Public. Les catégories émergentes de l'analyse de contenu ont révélé l'insuffisance (l'inadéquation) et la distance entre la langue et la culture des adolescents et le contenu de ces manuels rendus effectif comme instructifs et pédagogiques. Nous accentuons les aspects subjectifs et inconscients qui impliquent la reproduction humaine, en suggérant le néologisme "engravidamento" (“enceintement”) comme un processus psychique dans adolescence.

Mots-Cles: Devenir enceinte à l'adolescence. Sexualité féminine. Processus psychoterapeutique. 
Processos Psíquicos do Engravidamento na Adolescência em Contextos de Periferia

\section{Referências}

Bardin, L. (1977). Análise de conteúdo (L. A. Reto \& A. Pinheiro, trads.). Lisboa: Edições 70.

Bergès, J., \& Balbo, G. (2003). Há um infantil da psicose? (M. N. Folberg, trad.). Porto Alegre, RS: CMC.

Birman, J. (1999). Cartografias do feminino. São Paulo: Ed. 34.

Chemama, R. (2002). Elementos lacanianos para uma psicanálise no cotidiano. Porto Alegre, RS: CMC.

Corso, D. M. L. (2004). Édipo, latência e puberdade: a construção da adolescência. (pp. 131-145). In A. M. M. Costa et al (Orgs.), Adolescência e experiências de borda. Porto Alegre, RS: Editora da UFRGS.

Dolto, F., \& Dolto-Tolitch, C. (1993). Palavras para adolescentes: o el complexo de la langostra. Buenos Aires, Argentina: Atlântida.

Freud, S. (1981). Tres ensayos para una teoria sexual. In S. Freud, Obras completas (Vol. 2). Madrid, España: Biblioteca Nueva. (Trabalho original publicado em 1905)

Freud, S. (1981). Psicologia de las masas y analisis del yo. In S. Freud, Obras completas (Vol. 3). Madrid, España: Biblioteca Nueva. (Trabalho original publicado em 1920)

Jerusalinsky, A. (1997). Traumas de adolescência. In Adolescência entre o passado e o futuro. (pp. 11-27). Porto Alegre, RS: Artes e Ofícios.

Kehl, M. R. (2000). A pratria órfã: o esforço civilizatório do rap na periferia de São Paulo. In M. R. Kehl (Org.), Função fraterna (pp. 209-244). Rio de Janeiro: Relume Dumará.

Kristeva, J.(2002). As novas doenças da alma (J. A. D’Avila Melo, trad.). Rio de Janeiro: Rocco.

Lacan, J. (1978). Tempo lógico e a asserção de certeza antecipada: um novo sofisma. In J. Lacan, Escritos (pp. 69-86). São Paulo: Perspectiva. (Trabalho original publicado em 1966)

Ministério de Saúde. Secretaria de Políticas de Saúde. Área Técnica de Saúde da Mulher (2002). Assistência em planejamento familiar: manual técnico (4a ed.). Brasília, DF: autor.

Rassial, J-J. (1997). A passagem adolescente: da família ao laço social (F. A. H. Roche, trad.). Porto Alegre, RS: Artes e Ofícios. 


\section{Maria Aparecida Loss e Clary M. Sapiro}

Rassial, J.-J. (2004). Haveria uma psicopatologia das periferias? In A. Costa (Org.), Adolescência e experiências de borda (pp. 287-303). Porto Alegre, RS: Editora da UFRGS.

Reis, A. O. (1998). Análise metafórico-metonímica do processo de constituição do pensamento da saúde pública acerca da adolescente grávida: os anos 60. Caderno de Saúde Pública, 14(Supl. 1), 115-123.

Sant'anna, M. J. C. (2001). Gravidez: um enfoque atual. (pp. 61-72). In C. Weinberg, C. (Org.), Geração delivery: adolescer no mundo atual. São Paulo: Sá.

Recebido em: 16.08.2005

Revisto e encaminhado em: 07.11.2005

Aceito em: 05.12.2005 